\title{
Levantamento florístico de Myrtaceae no município de Jacobina, Chapada Diamantina, Estado da Bahia, Brasil
}

\author{
Aline Stadnik ${ }^{1,4}$, Marla Ibrahim U. de Oliveira ${ }^{2}$ e Nádia Roque ${ }^{3}$ \\ Recebido: 9.06.2015; aceito: 16.12.2015
}

\begin{abstract}
Floristic survey of Myrtaceae in Jacobina municipality, Chapada Diamantina, Bahia State, Brazil). Myrtaceae is a pantropical family with around 5500 species and 132 genera and is highlighted by its complex (cryptic characters) and difficult taxonomy. In Brazil, Myrtaceae is represented by 23 genera and 974 species and is one of the most representative in the Espinhaço Range. The main goal of this work was the floristic survey of Myrtaceae in Jacobina, Chapada Diamantina, Bahia. Five expeditions were conducted between June/2011 and April/2012; herbaria materials were examined in the State; and specialized references and Myrtaceae experts were consulted. Seven genera and 32 species of Myrtaceae were found and Myrcia DC. (14 spp.), Eugenia L. (nove spp.), and Psidium L. (quatro spp.) were the most representative, corresponding to $87 \%$ of total species. Myrcia blanchetiana (O. Berg) and Mattos is endemic to Bahia, two species (Eugenia rostrata O. Berg and Psidium brownianum DC.) are new occurrence to Jacobina and a new species of Myrcia has been recognized. Generic and specific keys are presented, as well as discussion about the morphology and geographical distribution of the taxa.
\end{abstract}

Keywords: Espinhaço Range, Myrcia, Serra do Tombador

RESUMO - (Levantamento florístico de Myrtaceae no município de Jacobina, Chapada Diamantina, Estado da Bahia, Brasil) Myrtaceae é uma família pantropical com cerca de 5500 espécies e 132 gêneros e que se destacada pela taxonomia complexa (caracteres crípticos) e difícil. No Brasil, Myrtaceae está representada por 23 gêneros e 974 espécies e é uma das famílias mais representativas na Cadeia do Espinhaço. O objetivo deste trabalho foi realizar o levantamento florístico de Myrtaceae no município de Jacobina, Chapada Diamantina, Bahia. Foram realizadas cinco expedições de coleta entre junho/2011 e abril/2012, analisado os materiais dos herbários no estado, consulta a bibliografias especializadas e especialistas da família. Foram encontrados sete gêneros e 32 espécies de Myrtaceae, sendo que Myrcia DC. (14 spp.), Eugenia L. (nove spp.) e Psidium L. (quatro spp.) foram os gêneros mais representativos, correspondendo a $87 \%$ do total de espécies. Myrcia blanchetiana (O.Berg) Mattos é endêmica para a Bahia, duas espécies (Eugenia rostrata O.Berg, Psidium brownianum DC.) são novas ocorrências para Jacobina e uma nova espécie de Myrcia foi reconhecida. São apresentadas chaves de identificações genéricas e específicas, além de discussões acerca da morfologia e distribuição geográfica dos táxons.

Palavras-chave: Cadeia do Espinhaço, Myrcia, Serra do Tombador

\section{Introdução}

A família Myrtaceae compreende ca. 142 gêneros e mais de 5.500 espécies, com distribuição pantropical, havendo dois principais centros de diversidade, América tropical e Austrália (Heywood et al. 2007, Wilson 2011). No Brasil, a família abrange 23 gêneros e cerca de 1.000 espécies (Sobral et al. 2015) e é considerada uma das famílias mais importantes economicamente, ocupando a oitava posição em diversidade no Nordeste (Sobral \& Proença 2006). Segundo McVaugh (1968), sua taxonomia é complexa, uma vez que as espécies se assemelham muito na maioria dos caracteres morfológicos. Por isso, faz-se necessário o uso de caracteres diagnósticos crípticos, como por exemplo, o número de estames no botão

1. Universidade Estadual de Feira de Santana, Departamento de Ciências Biológicas, Programa de Pós-Graduação em Botânica, Av. Transnordestina, s/n, 44036-900 Feira de Santana, BA, Brasil

2. Universidade Tiradentes, Centro de Ciências Biológicas e da Saúde. Av. Murilo Dantas, 300, Bloco E, Farolândia, $49032-490$ Aracaju, SE, Brasil

3. Universidade Federal da Bahia, Instituto de Biologia, Departamento de Botânica. Rua Barão de Geremoabo, s/n., Campus Universitário de Ondina, 40171-970 Salvador, BA, Brasil

4. Autor para correspondência: aline.stadnik8@gmail.com 
floral, o número de lóculos e de óvulos no ovário, o tipo de testa da semente e de embrião (Landrum \& Kawasaki 1997), o que dificulta a compreensão taxonômica e a delimitação específica.

Myrtaceae é umas das famílias mais representativas dentre as diversas fitofisionomias encontradas na Cadeia do Espinhaço (Bunger et al. 2014), que representa a segunda formação rochosa mais extensa do Brasil e que é constituída por dois blocos principais, a Chapada Diamantina, na Bahia e a Serra do Espinhaço, em Minas Gerais (Harley 1995, Giullietti et al. 1997).

Jacobina está localizado no limite norte da Chapada Diamantina e consiste de duas principais serras, a Serra do Tombador e a Serra da Jacobina, separadas por um grande vale. O município vem sofrendo com a perda de formação vegetacional nativa e sua área se encontra em processo de antropização devido à agricultura e pecuária, além das áreas industriais, urbanas, povoados, extrações de minérios e lajes de arenitos (Pedreira \& Rocha 2002, Pinheiro 2004).

Estudos florísticos em Myrtaceae têm se mostrado eficazes para o conhecimento e conservação dos táxons (Kawasaki 1989, Nic Lughadha 1995, Kawasaki 2004, Hatschbach et al. 2006, Bünger 2010), auxiliando na obtenção de informações e na delimitação específica. Sendo assim, o presente estudo teve como objetivo o levantamento florístico da família Myrtaceae no município de Jacobina, Chapada Diamantina, Bahia.

\section{Material e métodos}

Jacobina está localizada entre as coordenadas geográficas de $11^{\circ} 10^{\prime} \mathrm{S}$ e $40^{\circ} 30^{\prime} \mathrm{W}$, possuindo uma área de $2.319 \mathrm{~km}^{2}$. Situa-se entre duas formações montanhosas, a Serra do Tombador e a da Jacobina, encontrando-se a uma altitude média de $485 \mathrm{~m}$ acima do nível do mar (Pinheiro 2004) (figura 1).

O município tem uma vasta história acerca do seu território geográfico. Em meados do século XVII, Jacobina era conhecida como Vila de Jacobina e se estendia desde Rio de Contas, Bahia, até os limites de Sergipe, incluindo a Cachoeira de Paulo Afonso. Nesse período, o município foi percurso de coleta de alguns naturalistas, principalmente Jacques Samuel Blanchet (1807-1875), e só no fim do século XIX, o município foi reduzido ao que conhecemos hoje (Prefeitura Municipal de Jacobina 2015). Blanchet descreveu inúmeras espécies de angiospermas, com uma grande quantidade de materiais-tipo referidos a Jacobina.
O município está inserido em um cinturão de rochas metamórficas e sedimentares da unidade tectônica do São Francisco e é conhecido pelo seu grande potencial de extração de minérios, como o ouro (Mascarenhas \& Silva 1994). A vegetação predominante é a Caatinga (figura 2e), porém também apresenta áreas de Cerrado (figura $2 \mathrm{f}, \mathrm{g}$ ), Florestas Estacionais (figura 2b, c), Matas ciliares (figura 2a) e de grotão, além dos campos rupestres (figura 2d). Grande parte de suas áreas se encontra em estádios de antropização, porém as áreas nativas são compostas por refúgios ecológicos montanos e áreas de tensão ecológica (áreas transicionais). O clima varia entre seco, subúmido e semiárido, sofrendo forte influência da topografia; os meses de maiores precipitações estão entre janeiro e março (Pinheiro 2004).

Foram realizadas cinco expedições ao campo entre junho de 2011 a abril de 2012, visando alcançar a maior área do município de Jacobina, além de visitas aos herbários ALCB, HUEFS, MBM e HRB, a fim de auxiliar na comparação e identificação dos táxons encontrados. Os espécimes coletados foram herborizados, identificados e inseridos no Herbário Alexandre Leal Costa (ALCB), com duplicatas enviadas ao herbário AJU, HUEFS, HUFSJ, UB, US (acrônimos seguindo Thiers 2015).

A identificação específica foi feita com base em bibliografia especializada disponível para a família (Kawasaki 1989, Landrum \& Kawasaki 1997, Sobral 2007, Bunger 2010, Amorim \& Alves 2011 e Santos \& Sano 2012), protólogos e comparações com as coleções botânicas depositadas nos herbários visitados, além de consultas aos especialistas. A nomenclatura para os caracteres morfológicos seguiu Radford et al. (1974), Landrum \& Kawasaki (1997) e Harris \& Harris (2004).

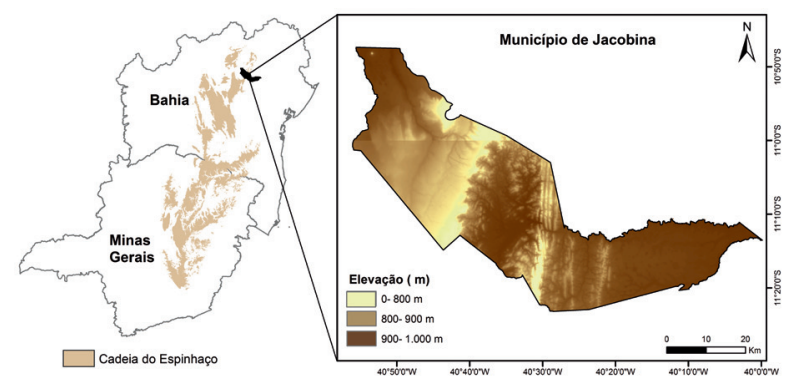

Figura 1. Cadeia do Espinhaço, localizada nos municípios de Bahia e Minas Gerais. Município de Jacobina.

Figure 1. Map of Espinhaço Range, located in the States of Bahia and Minas Gerais. Municipality of Jacobina. 


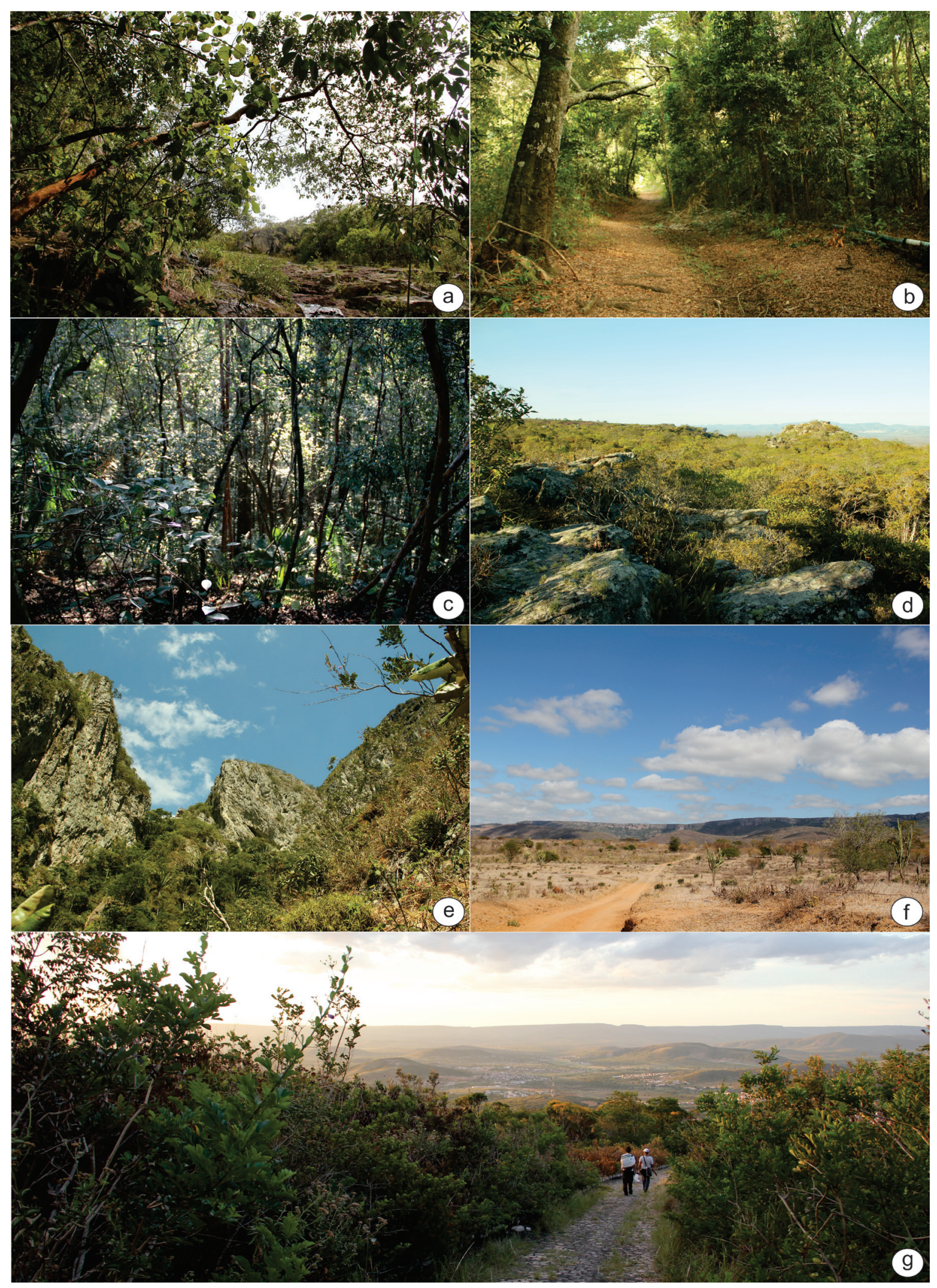

Figura 2. Fitofisionomias encontradas no município de Jacobina, Estado da Bahia, Brasil. a. Mata ciliar. b-c. Florestas semidesciduais. d-e. Campos rupestres. f. Caatinga. g. Cerrado. (Fotografias: L. Moura).

Figure 2. Phytophysiognomies found in the municipality of Jacobina, Bahia State, Brazil. a. Riparian Forest. b-c. Semidecidual Forest. d-e. Rocky field. f. Caatinga. g. Savanna. (Photo: L. Moura). 


\section{Resultados}

Foram reconhecidos para o município de Jacobina, sete gêneros e 32 espécies de Myrtaceae (tabela 1). Os gêneros mais representativos na área de estudo foram Myrcia DC. (14 spp.), seguido por Eugenia L. (nove spp.), Psidium L. (quatro spp.) e Myrciaria O. Berg (duas spp.), sendo que Blepharocalyx O. Berg, Campomanesia Ruiz e Pav. e Calyptranthes Sw. estão representados com uma espécie cada.

Dentre os principais resultados destacam-se uma espécie endêmica para a Bahia, Myrcia blanchetiana (O. Berg) Mattos, duas novas ocorrências para Jacobina (Eugenia rostrata O. Berg, Psidium brownianum DC.), e uma espécie nova de Myrcia para a Chapada Diamantina (Sobral et al. 2015). Oito espécies têm seu espécime-tipo coletado no município
[Campomanesia aromatica (Aubl.) Griseb, Eugenia cerassiflora Miq, Eugenia flavescens var. parvifolia (O. Berg), Eugenia ilhensis O. Berg, Eugenia ligustrina (Sw.) Willd., Myrcia calyptranthoides DC., Myrcia neoblanchetiana E. Lucas \& Sobral e Myrcia reticulosa Miq.], das quais apenas Myrcia calyptranthoides foi recoletada. Do restante, sete espécies são amplamente distribuídas no Brasil [Eugenia punicifolia (Kunth) DC., Myrcia amazonica DC., Myrcia guianensis (Aubl.) DC., Myrcia splendens (Sw.) DC., Myrcia tomentosa (Aubl.) DC., Myrciaria floribunda (H. West ex Willd.) O. Berg e Psidium guineense Sw.].

Entre as diversas fitofisionomias descritas para Jacobina (SEI 2007, Pinheiro 2004), as áreas de mata (17 spp.) e Cerrado (16 spp.) apresentaram maior riqueza de Myrtaceae, seguidos por campos rupestres (oito spp.), Caatinga e áreas de transição (cinco spp.) (tabela 1).

Chave de identificação para os gêneros, incluindo aqueles com uma única espécie, encontrados no município de Jacobina

\section{Inflorescências em dicásio}

2. Botões com cálice aberto, na antese abrindo em quatro lobos calicinais; lobos decíduos no fruto deixando uma cicatriz quadrada; testa da semente fina e delicada Blepharocalyx salicifolius

2. Botões com lobos fechados, na antese abrindo em lobos irregulares; lobos persistentes no fruto; testa da semente extremamente dura (pétrea) Psidium

1. Inflorescências em panículas ou racemos ou flores solitárias

3. Inflorescência em panícula; semente com embrião myrcioide

4. Botão com cálice aberto, na antese abrindo em cinco lobos calicinais Myrcia

4. Botão com cálice fechado, na antese abrindo em uma caliptra Calyptranthes rufa

3. Inflorescência em racemos, fascículos ou flores solitárias; semente com embrião myrtoide ou eugenioide

5. Flores tetrâmeras, sempre com lobos abertos após a antese; ovário com dois lóculos; embrião eugenioide

6. Tubo do cálice (hipanto) não prolongado acima do ovário; ovário multiovulado (mais de quatro óvulos por lóculo) Eugenia

6. Tubo do cálice (hipanto) prolongado acima do ovário e decíduo após a antese, deixando uma pequena cicatriz circular no fruto; ovário com dois óvulos por lóculo Myrciaria

5. Flores pentâmeras ou com cálice fechado, abrindo-se em lobos irregulares na antese; ovário com três ou mais lóculos; embrião myrtoide

7. Óvulos inseridos em placenta invadindo os lóculos do ovário, lóculos sem glândulas Psidium

7. Óvulos inseridos em placenta não invadindo os lóculos do ovário, lóculos com glândulas

Campomanesia aromatica

Chave de identificação para as espécies de Eugenia

\section{Flores solitárias}

2. Lâmina foliar elíptica, amarelada quando seca; bractéolas cordadas, conspícuas, ca. $20 \mathrm{~mm}$ de compr.; lobos calicinais (ca. $15 \mathrm{~mm}$ de compr.)

2. Lâmina foliar oblanceolada, verde quando seca; bractéolas ovadas, inconspícuas, ca. $1 \mathrm{~mm}$ de compr.; lobos calicinais (ca. $2 \mathrm{~mm}$ de compr.) E. punicifolia

1. Inflorescências em racemos, fascículos ou glomérulos

3. Flores dispostas em fascículos 
4. Lâmina foliar concolor ou levemente discolor, ápice apiculado, base atenuada, margem plana, face adaxial fosca E. rostrata

4. Lâmina foliar acentuadamente discolor, ápice obtuso, base arredondada, margem ondulada, face adaxial lustrosa . E. cerasiflora

3. Flores dispostas em racemos ou glomérulos

5. Flores dispostas em racemos

6. Lâmina foliar obovada; racemos auxotélicos, brácteas vináceas (1,2-3,8 mm compr.), lobos calicinais longos (1,7-3,2 mm compr.) lanceolados

6. Lâmina foliar elíptica; racemo bem desenvolvido, brácteas castanhas (0,1-0,5 mm compr.) lobos calicinais curtos $(0,6-1 \mathrm{~mm})$, arredondados .... E. candolleana

5. Flores dispostas em glomérulos

7. Folhas e flores amareladas quando secas; lâmina foliar lanceolada com venação não evidente; bractéolas curtas (0,8-1 mm compr.) E. flavescens var. parvifolia

7. Folhas e flores verdes escuras quando secas; lâmina foliar elíptica a arredondada com venação evidente; bractéolas 0,3-0,5 mm compr.

8. Lâmina foliar com face adaxial lustrosa; lobos calicinais inconspícuos (0,8-1,1 mm compr.)

E. sonderiana

8. Lâmina foliar com face adaxial opaca; lobos calicinais conspícuos (3 mm compr.) E. ilhensis

Chave de identificação para as espécies de Myrcia

1. Lâmina foliar elíptica

2. Flores com dois lóculos no ovário

3. Ramo da inflorescência e flores com indumento alvo a hialino

4. Lâmina foliar coriácea, com ápice agudo e glândulas pouco evidentes, ca. 100-200 glândulas por $\mathrm{cm}^{2}$; flores pediceladas

M. blanchetiana

4. Lâmina foliar cartácea, com ápice caudado e glândulas muito evidentes, ca. 500-600 glândulas por $\mathrm{cm}^{2}$; flores sésseis M. calyptranthoides

3. Ramo da inflorescência e flores com indumento ferrugíneo

5. Lâmina foliar 5-14 cm compr., ápice arredondado ou acuminado a caudado; indumento viloso denso nos ramos jovens, inflorescências e botões

6. Caule avermelhado; hipanto constricto acima do ovário

M. amazonica

6. Caule esbranquiçado; hipanto não constricto acima do ovário

7. Lâmina foliar elíptica, ápice arredondado, 10-20 pares de nervuras secundárias; antera sem glândula no ápice M. pubescens

7. Lâmina foliar ovada, ápice acuminado, 40-60 pares de nervuras secundárias; antera com uma glândula no ápice

M. mutabilis

5. Lâmina foliar 2-4 cm compr., ápice agudo; indumento puberulento nos ramos jovens, inflorescências e botões

M.jacobinensis

2. Flores com três lóculos no ovário

8. Botões glabros; hipanto não constricto na altura do ovário; parte interna dos lobos calicinais com tricomas hialinos; frutos glabros M. guianensis

8. Botões com indumento viloso; hipanto constricto na altura do ovário; parte interna dos lobos calicinais glabra; frutos pubescentes M. tomentosa

1. Lâmina foliar oblonga, ovada ou lanceolada

9. Inflorescência pauciflora (7-20 flores); botões 0,5-0,7 cm compr.; glândulas no ápice da antera

10. Folhas cartáceas; flores com sépalas reflexas $(0,3 \times 0,3 \mathrm{~cm})$; pétalas largamente elípticas a circulares, ápice arredondado M. rosangelae

10. Folhas membranáceas; flores com sépalas inflexas $(0,15 \times 0,15 \mathrm{~cm})$; pétalas ovadas com ápice agudo M. neoblanchetiana

9. Inflorescência multiflora (30-100 flores); botões 0,1-0,3 cm compr.; sem glândulas no ápice da antera 
11. Plantas glabras ou glabrescentes; lâmina foliar lanceolada

12. Lâmina foliar (10-20 cm compr.), glabra, venação adaxial saliente M. splendens

12. Lâmina foliar (1-7 cm compr.), indumento hialino estrigoso, venação adaxial sulcada M. sylvatica

11. Plantas com indumento tomentoso denso; lâmina foliar ovada

13. Planta com indumento ferrugíneo; lâmina foliar com glândulas evidentes, nervuras secundárias salientes na face abaxial; hipanto não constricto acima do ovário M. reticulosa

13. Plantas com indumento alvo a cinza; lâmina foliar sem glândulas evidentes, nervuras secundárias não evidentes na face abaxial; hipanto constricto acima do ovário .......... M. pseudovenulosa

Chave de identificação para as espécies de Myrciaria

1. Lâmina foliar com margem revoluta e ápice agudo, venação principal e pecíolo com coloração diferente da lâmina, face adaxial lustrosa; botões lustrosos; frutos amarelos quando maduros M. glanduliflora

1. Lâmina foliar com margem plana e ápice apiculado, venação principal e pecíolo com mesma coloração da lâmina, face adaxial opaca; botões opacos; frutos vermelhos quando maduros M. floribunda

Chave de identificação para as espécies de Psidium

1. Cálice fechado, na antese abrindo-se em lobos irregulares, lineares

2. Flores em dicásios P. guineense

2. Flores solitárias

3. Folhas pecioladas (0,3-0,5 $\mathrm{cm}$ compr.), lâmina foliar lanceolada, base aguda, ápice acuminado P. oligospermum

3. Folhas sésseis a subsésseis (até $0,1 \mathrm{~cm}$ compr.), lâmina foliar elíptica, base e ápice arredondados P. brownianum

1. C álice aberto, na antese abrindo-se em cinco lobos regulares, em formato de crista

P. shenckianum

\section{Discussão}

A taxonomia de Myrtaceae é definida por caracteres de difícil compreensão e visualização (caracteres crípticos). Como subsídios à chave genérica apresentada são discutidos abaixo os principais caracteres diagnósticos utilizados no reconhecimento de gêneros em Myrtaceae.

O tipo de embrião é um dos caracteres mais complexos e na área de estudo foram observados os três tipos básicos (Landrum \& Kawasaki 1997): embriões mircioides (cotilédones finos, foliares, enrolados, radícula longa e encurvada) em Myrcia e Calyptranthes; embriões eugenioides (cotilédones fundidos concrescidos em uma massa homogênea, radícula indeterminada) em Eugenia e Myrciaria; e embriões mirtoides (cotilédones pequenos separados por uma radícula bastante evidente, encurvada) presentes nas espécies de Psidium e Campomanesia.

A arquitetura da inflorescência também tem um grande valor taxonômico para os gêneros e suas seções. Nas Myrtaceae de Jacobina foram observadas inflorescências paniculiformes em todas as espécies de Myrcia e Calyptranthes rufa (figuras $3 b, f, i)$, além das inflorescências racemiformes em Eugenia. Espécies com flores solitárias, consideradas como inflorescências reduzidas a uma única flor (mônades) (Briggs \& Johnson 1979), foram observadas em Eugenia punicifolia, E. involucrata, Psidium brownianum e P. schenckianum (figura 3j). Inflorescências em fascículos são arranjos onde o eixo floral é curto e as flores pediceladas (E. flavescens var. parvifolia, E. ilhensis), mas se as flores forem sésseis ou subsésseis, a inflorescência é chamada de glomérulo como em Myrciaria. Inflorescências em dicásio foram observadas em Blepharocalyx salicifolius e Psidium guineense.

A fusão, prefloração e o número de lobos calicinais também colaboraram para o reconhecimento dos gêneros nas Myrtaceae de Jacobina. Os lobos podem variar entre prefloração valvar ou imbricada, serem fusionados ou livres entre si, e ainda possuir de 4 a 6 lobos (Landrum \& Kawasaki 1997, Bünger 2010). Das espécies coletadas na área, observa-se o cálice com lobos imbricados e livres nas espécies de Blepharocalyx, Eugenia e Myrciaria (cálice tetrâmero) e em todas as espécies de Myrcia (cálice pentâmero). Já em Psidium, Campomanesia e Calyptranthes são observados os lobos calicinais com prefloração valvar, fundidos e na antese abrindo-se de maneira irregular, variando no número de lobos (3-6 lobos). Em Calyptranthes o cálice é distinto por formar uma caliptra.

Myrcia mostrou-se extremamente diversa em Jacobina, uma vez que das 20 espécies listadas para a 
Tabela 1: Lista das espécies de Myrtaceae para o município de Jacobina, Bahia, incluindo o voucher (ALCB) e as fitofisionomias associadas (Ce: Cerrado, Cr: Campo rupestre, Mc: Mata ciliar, Fe: Floresta Estacional, Ca: Caatinga, N.I.: não identificado).

Table 1: List of Myrtaceae species in the municipalily of Jacobina, Bahia, including the voucher (ALCB) and associated vegetation types (Ce: Savanna, Cr: Rocky field, Mc: Riparian Forest, Fs: Semidecidual Forest, Ca: Caatinga, NI: not identified).

\begin{tabular}{|c|c|c|}
\hline Gênero/espécie & Voucher & Fitofisionomia \\
\hline \multicolumn{3}{|l|}{ Blepharocalyx } \\
\hline Blepharocalyx salicifolius (Kunth) O. Berg & A. Stadnik et. al. 63 & $\mathrm{Ce}, \mathrm{Ca}, \mathrm{Cr}$ \\
\hline \multicolumn{3}{|l|}{ Calyptranthes } \\
\hline Calyptranthes rufa O. Berg & A. Stadnik et. al. 54 & $\mathrm{Ce}, \mathrm{Fe}, \mathrm{Mc}$ \\
\hline \multicolumn{3}{|l|}{ Campomanesia } \\
\hline Campomanesia aromatica (Aubl.) Griseb & J.S. Blanchet 3367 & N.I. \\
\hline \multicolumn{3}{|l|}{ Eugenia } \\
\hline Eugenia candolleana DC. & A. Stadnik et. al. 63 & $\mathrm{Fe}$ \\
\hline Eugenia cerassiflora Miq. & J.S. Blanchet 3727 & $\mathrm{Cr}$ \\
\hline Eugenia flavescens var. parvifolia $\mathrm{O}$. Berg & J.S. Blanchet 2791 & N.I. \\
\hline Eugenia ilhensis O. Berg & J.S. Blanchet 2655 & N.I. \\
\hline Eugenia involucrata DC & A. Stadnik et. al. 58 & $\mathrm{Mc}$ \\
\hline Eugenia ligustrina (Sw.) Willd. & J.S. Blanchet 2572 & $\mathrm{Ce}, \mathrm{Fe}$ \\
\hline Eugenia punicifolia (kunth) DC. & A. Stadnik et. al. 1 & $\mathrm{Ce}, \mathrm{Ca}, \mathrm{Fe}, \mathrm{Cr}$ \\
\hline Eugenia rostrata $\mathrm{O}$. Berg & A. Stadnik et. al. 60 & $\mathrm{Fe}$ \\
\hline Eugenia sonderiana $\mathrm{O}$. Berg & A. Stadnik et. al. 42 & $\mathrm{Ce}, \mathrm{Cr}$ \\
\hline \multicolumn{3}{|l|}{ Myrcia } \\
\hline Myrcia amazonica DC. & A. Stadnik et. al. 55 & $\mathrm{Mc}, \mathrm{Fe}$ \\
\hline Myrcia blanchetiana (O.Berg) Mattos & A. Stadnik et. al. 57 & $\mathrm{Cr}$ \\
\hline Myrcia calyptranthoides DC. & A. Stadnik et. al. 50 & $\mathrm{Ce}, \mathrm{Fe}$ \\
\hline Myrcia guianensis (Aubl.) DC. & A. Stadnik et. al. 31 & $\mathrm{Ce}, \mathrm{Ca}, \mathrm{Fe}, \mathrm{Cr}$ \\
\hline Myrcia jacobinensis Mattos & A. Stadnik et. al. 56 & $\mathrm{Cr}, \mathrm{Ca}$ \\
\hline Myrcia mutabilis (O. Berg) N.Silveira & A. Stadnik et. al. 37 & $\mathrm{Fe}$ \\
\hline Myrcia neoblanchetiana E. Lucas \& Sobral & J.S. Blanchet 3415 & Mc \\
\hline Myrcia pseudovenulosa Stadnik \& Sobral & A. Stadnik et. al. 64 & $\mathrm{Ce}, \mathrm{Cr}$ \\
\hline Myrcia pubescens DC. & A.M. Giulietti et al. PCD2702 & $\mathrm{Fe}$ \\
\hline Myrcia reticulosa Miq & J.S. Blanchet 3728 & N.I. \\
\hline Myrcia rosangelae NicLugh. & M.L. Guedes et al. PCD 2651 & $\mathrm{Mc}$ \\
\hline Myrcia splendens (Sw.) DC. & A. Stadnik et. al. 25 & $\mathrm{Ce}, \mathrm{Fe}$ \\
\hline Myrcia sylvatica (G. Mey.) DC. & A. Stadnik et. al. 35 & $\mathrm{Ce}, \mathrm{Fe}$ \\
\hline Myrcia tomentosa (Aubl.) DC. & A. Stadnik et. al. 41 & $\mathrm{Ce}$ \\
\hline \multicolumn{3}{|l|}{ Myrciaria } \\
\hline Myrciaria floribunda (H.West ex Willd.) O. Berg & A. Stadnik et. al. 61 & $\mathrm{Ce}$ \\
\hline Myrciaria gladulifolia (Kiaersk.) Mattos \& D. Legrand & A.M. Giulietti PCD 2823 & $\mathrm{Fe}$ \\
\hline \multicolumn{3}{|l|}{ Psidium } \\
\hline Psidium brownianum DC. & A. Stadnik et. al. 46 & $\mathrm{Ce}$ \\
\hline Psidium guineense $\mathrm{Sw}$. & A. Stadnik et al. 4 & $\mathrm{Ce}, \mathrm{Fe}$ \\
\hline Psidium oligospermum DC. & A. Stadnik et. al. 3 & $\mathrm{Ce}, \mathrm{Ca}$ \\
\hline Psidium schenckianum Kiaersk & A. Stadnik et al. 62 & $\mathrm{Ce}$ \\
\hline
\end{tabular}



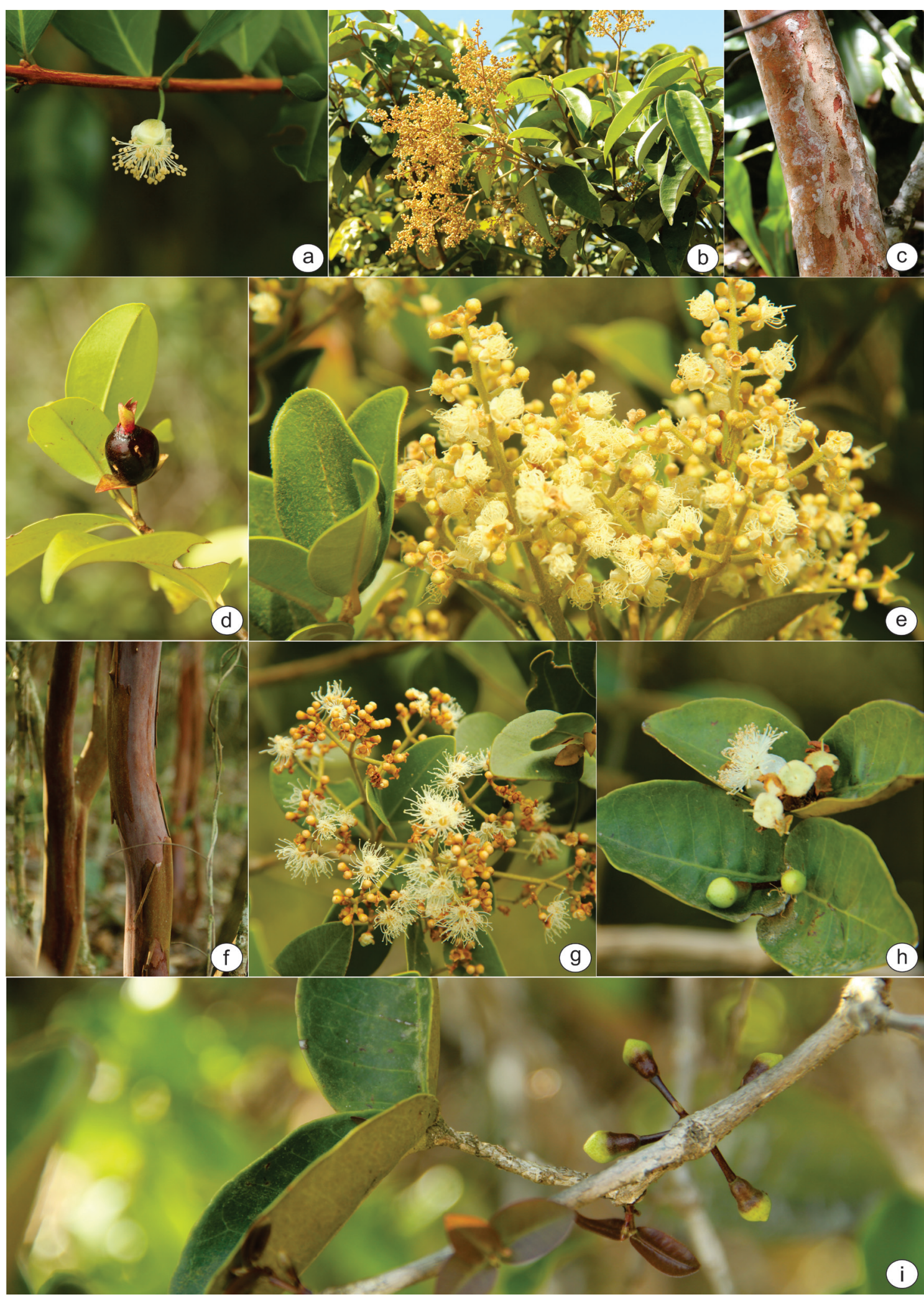

Figura 3. Espécies de Myrtaceae no município de Jacobina, Estado da Bahia, Brasil. a. Eugenia punicifolia. b-c. Myrcia amazonica. d. Eugenia involucrata. e. Myrcia blanchetiana. f. Eugenia candoleana. g. Myrcia jacobinensis. h-i. Psidium brownianum (Fotografia: L. Moura).

Figure 3. Myrtaceae species in the municipality of Jacobina, Bahia State, Brazil. a. Eugenia punicifolia. b-c. Myrcia amazonica. d. Eugenia involucrata. e. Myrcia blanchetiana. f. Eugenia candoleana. g. Myrcia jacobinensis. h-i. Psidium brownianum. (Photos: L. Moura). 
Chapada Diamantina, 14 foram coletadas no município. M. rosangelae NicLugh. e M. neoblanchetiana foram encontradas apenas em áreas de matas ciliares, próximas aos córregos. Myrcia amazonica, por sua vez, foi coletada principalmente em matas ciliares, embora ocorra também em florestas estacionais. Dentre essas espécies, $M$. amazonica pode ser reconhecida pelo tronco avermelhado e inflorescência com numerosas flores (60-100), diferente das duas anteriores que apresentam um tronco acinzentado e inflorescências com poucas flores (7-20) (vide chave).

Myrcia calyptranthoides, M. mutabilis (O. Berg) N. Silveira e M. pubescens DC. são espécies predominantemente encontradas em florestas estacionais. A primeira foi coletada também em Cerrado e distingue-se das demais pelo caule e folhas glabrescentes e frutos róseos glabros ( $v s$. caule e folhas com indumento ferrugíneo e frutos tomentosos). M. mutabilis e M. pubescens diferem-se pelo tipo de indumento (tomentoso vs. pubescente), além do formato da lâmina (ovada vs. elíptica), respectivamente, e em $M$. mutabilis é visível uma glândula apical na antera.

Espécies como Myrcia sylvatica e M. tomentosa são extremamente abundantes nas áreas de cerrado de Jacobina, sendo a última coletada apenas nesse ambiente. São completamente distintas pelo formato da folha, indumento, tamanho do pedicelo, forma e disposição dos lobos calicinais (vide chave).

Myrcia blanchetiana e M. pseudovenulosa Stadnik \& Sobral foram encontradas em Jacobina apenas em vegetação de campos rupestres. Ambas, cobertas com denso indumento alvo, hialino ou acinzentado. A primeira foi coletada em afloramentos rochosos e caracteriza-se pelas folhas elípticas, ovário com dois lóculos, enquanto M. pseudovenulosa, uma espécie recentemente descrita para a Chapada Diamantina, foi encontrada em ambientes de campo rupestre e Cerrado e pode ser reconhecida pelas folhas ovadas e três lóculos no ovário.

Eugenia é o segundo gênero mais diverso na área de estudo com nove espécies. Dentre elas, Eugenia flavescens é conhecida por duas variedades: $E$. flavescens var. flavescens O. Berg, espécie de ampla distribuição no Brasil e E. flavescens var. parvifolia O. Berg, espécie endêmica de Jacobina e conhecida apenas pelo material tipo. Esta circunscrição não tem sido utilizada pelos especialistas, entretanto, através das observações em herbários, notam-se dois morfotipos bem estabelecidos: em E. flavescens var. parvifolia a lâmina é membranácea, com grandes glândulas sobressaindo na face adaxial (vistas a olho $\mathrm{nu}$ ) e venação não evidente; em E. flavescens var. flavescens a lâmina é cartácea, pequenas glândulas inconspícuas na superfície adaxial (apenas vistas sob transparência) e venação evidente. A distinção entre os morfotipos na espécie fortalecerá o conhecimento e a distribuição geográfica das variedades.

Eugenia sonderiana O. Berg e Eugenia punicifolia são facilmente confundidas, uma vez que a morfologia floral, o tamanho e formato da lâmina foliar e o habitat são similares. Essas espécies podem ser distinguidas principalmente pelos frutos, que em E. sonderiana são arredondados e atropurpúreos quando maduros, enquanto em E. punicifolia, os frutos são elípticos e vermelhos quando maduros. Na área de estudo, ambas foram coletadas em campos rupestres e florestas estacionais. Eugenia punicifolia é amplamente distribuída e ocorre em todas as fitofisionomias brasileiras (Sobral et al. 2015) e apresenta uma ampla variação morfológica, principalmente em sua morfologia floral. Sobral (1987) descreveu $E$. punicifolia como tendo flores solitárias, e raramente formando um eixo curto com 2 ou 4 flores. Giaretta \& Peixoto (2015), por sua vez, descreveram sua inflorescência como flores fasciculadas, e Amorim \& Alves (2011), como racemos curtos, com dois eixos secundários. Contudo, os indivíduos coletados em Jacobina apresentaram somente flores solitárias.

Eugenia involucrata DC. é facilmente distinguível das demais pelas bractéolas foliares e lobos do cálice conspícuos (figura 3d). Na área de estudo, a espécie foi coletada sob afloramentos rochosos em matas ciliares. Eugenia ligustrina (Sw.) Willd. foi coletada em áreas de Cerrado e Florestas Estacionais e se diferencia das demais pelas brácteas conspícuas e vináceas na base das flores (racemo auxotélico).

Myrciaria está representada em Jacobina por M. floribunda e M. glanduliflora (Kiaersk.) Mattos \& D. Legrand que, à primeira vista, são similares. Contudo, a primeira tem lâmina com margem revoluta, com glândulas inconspícuas nos botões e frutos; enquanto que $M$. granduliflora tem lâmina foliar com margem plana, com glândulas evidentes e em grande quantidade nas flores e botões, dando a impressão lustrosa. $\mathrm{Na}$ área de estudo, M. floribunda foi coletada em ambientes de Cerrado e M. glanduliflora em ambientes de Florestas estacionais.

Em Psidium, o cálice é uma das principais características no reconhecimento de espécies. No botão, o cálice pode ser livre ou fundido: Psidium brownianum (figura 3c), P. guineense, P. oligospermum 
DC. apresentam o cálice totalmente fechado, com os lobos partindo de forma irregular na antese. Esta última espécie pode apresentar uma abertura similar a uma caliptra, pois na antese o cálice pode romper-se de forma circular no botão. Já em P. schenckianum Kiaersk., o cálice é totalmente livre no botão e em forma de crista, característico da espécie. Todas as espécies foram coletadas em ambientes de Cerrado, sendo $P$. guineense também coletada em ambientes de florestas estacionais e $P$. schenckianum em áreas de Caatinga.

Blepharocalyx salicifolius é conhecida pela sua grande plasticidade fenotípica, principalmente no formato das folhas (Landrum 1986). Em Jacobina, a espécie foi coletada em ambientes de campos rupestres e pode ser caracterizada pelas folhas ovadas $(2,3-4 \mathrm{~cm}$ compr.), venação evidente e frutos vermelhos quando maduros.

Calyptranthes rufa, única espécie do gênero citada para Jacobina, foi encontrada em ambientes de matas ciliares e florestas estacionais. A espécie é distinguida pelos ramos dicotômicos, indumento tomentoso ferrugíneo nos ramos jovens, lâmina foliar, inflorescência, flores e frutos.

Jacobina apresenta $64 \%$ de suas formações vegetacionais em processo de antropização (Pinheiro 2004). Embora a vegetação nativa se encontre reduzida, este estudo permitiu reunir dados inéditos de Myrtaceae envolvendo a taxonomia, distribuição, endemismos e uma espécie nova para a ciência, reforçando assim, a importância de trabalhos florísticos e a necessidade de proteção e conservação das áreas verdes do país.

\section{Agradecimentos}

As autoras agradecem ao projeto PRONEM (PNE 1642/2011) pelos recursos oferecidos para as viagens de campo. Ao Dr. Marcos Sobral e Dr. Matheus Fontes pelas valiosas discussões e auxílio nas identificações. À Lídia Campos pela confecção do mapa. Aos guias Silviano Santos e Amilton Oliveira pelo apoio durante as coletas de material. Ao CNPq pelas bolsas concedidas à primeira (IC) e última (PQ) autoras.

\section{Literatura citada}

Amorim, B.S. \& Alves, M. 2011. Flora da Usina São José, Igarassu, Pernambuco: Myrtaceae. Rodriguésia. 62: 499-514.

Barroso, G.M. 1991. Sistemática de Angiospermas do Brasil. Universidade Federal de viçosa. v. 2. Imprensa Universitária, Viçosa.
Briggs, B.G. \& Johnson, L.A.S. 1979. Evolution in the Myrtaceae - Evidence from inflorescence structure. Proceedings of the Linnean Society of New South Wales 102: 157-254.

Bünger, M. 2010. Myrtaceae na cadeia do espinhaço: A flora do Parque Estadual do Itacolomi (Ouro Preto) e uma análise das relações florísticas e da influência das variáveis geoclimáticas na distribuição das espécies. Dissertação de Mestrado. Universidade Federal de Minas Gerais, Minas Gerais.

Bünguer, M., Stehman, J.R., Oliveira-Filho, A.T. 2014. Myrtaceae throughout the Espinhaço Mountain Range of centraleastern Brazil: floristic relationships and geoclimatic controls. Acta Botanica Brasilica 28: 109-119.

Giulietti, A.M., Pirani, J.R. \& Harley, R.M. 1997. Espinhaço Range region. In: S. Davis, V.H. Heywood, O. Herrera MacBryde, J. Villa-Lobos \& A.C. Hamilton (eds.). Centers of plant diversity: a guide \& strategy for their conservation. v. 1. Cambridge University Press, Cambridge, Reino Unido, pp 397-404.

Harley, R.M. 1995. Introduction. In: B.L. Stannard (ed.). Flora of the Pico das Almas, Chapada Diamantina, Bahia, Brasil. Royal Botanic Gardens, Kew.

Harris, J.G. \& Harris, M.W. 2004. Plant Identification Terminology: An Illustrated Glossary. Utah: Spring Lake Publishing.

Hatschbach, G., Guarçoni, E.A.E., Sartori, M.A. \& Ribas, O.S. 2006. Aspectos fisionômicos da vegetação da Serra do Cabral, Minas Gerais-Brasil. Boletim do Museu Botânico Municipal 67: 1-33.

Heywood, V. H., Brummit, R.K., Culham, A \& Seberg, O. 2007. Flowering plant families of the world. Canadá, Firefly Books, pp. 225-226.

Kawasaki, M.L. 1989. Flora da Serra do Cipó, Minas Gerais: Myrtaceae. Boletim de Botânica da Universidade São Paulo 11: 121-170.

Kawasaki, M.L. 2004. Flora de Grão-Mogol, Minas Gerais: Myrtaceae. Boletim de Botânica da Universidade de São Paulo 22: 323-337.

Landrum, L.R. 1986. Campomanesia, Pimenta, Blepharocalyx, Legrandia, Acca, Myrrhinium and Luma (Myrtaceae). Flora Neotropica Monograph 45: 65-66.

Landrum, L.R. \& Kawasaki, M.L. 1997. The genera of Myrtaceae in Brazil: an illustrated synoptic treatment and identification keys. Brittonia 49: 508-536.

Lughadha, E. 1995. Myrtaceae. In: B.L. Stannard (ed.). Flora of the Pico das Almas. Royal Botanic Gardens, Kew, pp. 492-517.

Mascarenhas, J.F. \& Silva, E.F.A. 1994. Greenstone belt de mundo novo: caracterização e implicações metalogenéticas e geotectônicas no Cráton do São Francisco. Série Arquivos Abertos 5: 1-31. 
McVaugh, R. 1968. The genera of american Myrtaceae - an interim report. Taxon 17: 354- 418.

Pedreira, A.J. \& Rocha, A.J.D. 2002. Serra do Tombador, Chapada Diamantina, BA - Registro de um deserto proterozóico. In: C. Schobbenhaus, D.A. Campos, E.T. Queiroz, M. Winge, M.L.C. Berbert-Born (ed.). Sítios Geológicos e Paleontológicos do Brasil. 1. ed. Brasilia: DNPM/CPRM - Comissão Brasileira de Sítios Geológicos e Paleobiológicos (SIGEP).

Pinheiro, C.F. 2004. Avaliação geoambiental do muncípio de Jacobina-BA através das técnicas de geoprocessamento: um suporte ao ordenamento territorial. Dissertação de Mestrado, Universidade Federal da Bahia, Salvador.

Prefeitura Municipal de Jacobina. 2015. Histórico da cidade de Jacobina. Disponível em http://www.jacobina. ba.gov.br/v1/?p=28 (acesso em 22-V-2015).

Radford, A.E, Dickison, W.C, Massey, J.R., Bell, C.R. 1974. Vascular Plant Systematics. Harper \& Row Publishers, New York.

Santos, M.F \& Sano, P.T. 2012. Flora fanerogâmica da Serra do Ouro Branco, Minas Gerais: Myrtaceae. Rodriguésia 63: 1065-1083.

Superintendência de Estudos Econômicos e Sociais da Bahia - SEI. 2007. Informações ambientais, Revista Brasileira de Botânica 13: 19-25. Disponível em www. sei.ba.gov.br (acesso em 15-X-2007).
Sobral, M. 2007. A evolução do conhecimento taxonômico das angiospermas no Brasil (1990-2006) e um estudo de caso: a família Myrtaceae no município de Santa Teresa, Espírito Santo. Tese de Doutorado, Universidade Federal de Minas Gerais, Belo Horizonte.

Sobral, M. \& Proença, C.E.B. 2006. Siphoneugena delicata (Myrtaceae), a new species from the Montane Atlantic Forests of Southeastern Brazil. Novon 16: 530-532.

Sobral, M., Proença, C., Souza, M., Mazine, F., Lucas, E. 2015. Myrtaceae in Lista de Espécies da Flora do Brasil. Jardim Botânico do Rio de Janeiro. Disponível em http://floradobrasil.jbrj.gov.br/jabot/floradobrasil/ FB171 (acesso em: 22-V-2015).

Sobral, M., Faria Jr., J.E.Q., Oliveira, M.I.U. , Lucas, E.J., Rigueira, D., Stadnik, A., Villaroel, D. 2015. Thirteen new Myrtaceae from Bahia, Brazil. Phytotaxa 224: 201-231.

Thiers, B. 2015. Index Herbariorum: a global directory of public herbaria and associated staff. New York Botanical Garden's Virtual Herbarium. Disponível em http:// sweetgum.nybg.org/ih/ (acesso em 16-V-2015).

Wilson, P.G. 2011. Myrtaceae. In: K. Kubitzki (ed.). Flowering plants. Eudicots: The families and genera of vascular plants. v. 10. Springer, Berlin, Heidelberg, pp. 212-271. 